\title{
Metodologias
}

\section{Metodologia quantitativa em pesquisas sobre cobertura jornalística: análise da eleição municipal de 2012 na Folha de S. Paulo}

Quantitative metods in research on journalistic coverage: analysis of the 2012 municipal election in the Folha de S. Paulo

EMERSON URIZZI CERVI

Professor do Departamento de Ciências Sociais, da Pós-Graduação em Ciência Política e da Pós-Graduação em Comunicação da Universidade Federal do Paraná (UFPR) - Curitiba, PR, Brasil.

$<$ ecervi7@gmail.com>

MiCHELE GOULART MASSUCHIN

Doutoranda em Ciência Política da Universidade Federal de São Carlos (UFSCar) - São Carlos, SP, Brasil.

<mimassuchin@gmail.com>

\section{RESUMO}

$\mathrm{O}$ artigo divide-se em duas partes. A primeira apresenta aspectos do método de análises da cobertura jornalística em veículos tradicionais. A segunda é um teste empírico da metodologia apresentada anteriormente. Para o teste é analisado o padrão de cobertura da Folha de S. Paulo nas eleições para prefeitura de São Paulo, em 2012. A metodologia quantitativa é usada para acompanhar a produção jornalística sobre eleições, partindo da importância que a mídia tem para o

\section{ABSTRACT}

The paper is divided into two parts. The first presents aspects of the analysis method of news coverage in traditional vehicles. The second is an empirical test of this methodology. For the test is considered the standard of Folha de S. Paulo cover in the elections for mayor of São Paulo, in 2012. The quantitative methodology is used to monitor the journalistic production, starting from the importance that the media have to the debate and the public agenda 
debate e agenda pública (McCombs, 2009). O objetivo do artigo é verificar como isso se aplica à cobertura da eleição de 2012. Para tanto, faz uma breve discussão metodológica para expor as variáveis utilizadas e analisa a Folha de S. Paulo durante o período eleitoral de 2012, tendo como foco a cobertura dos candidatos Fernando Haddad (PT), José Serra (PSDB) e Celso Russomano (PRB). Os resultados indicam que a Folha de $S$. Paulo reforça uma tendência de preferência eleitoral existente na cidade, o que contraria a hipótese do agendamento.

Palavras-chave: Cobertura Eleitoral; Metodologia Quantitativa; Agenda-Setting.
(McCombs, 2009). The objective of this paper is to see how shape the coverage of the election of 2012. Therefore, a brief discussion on methods to expose the variables used and analyzes the Folha de S. Paulo during the 2012 election, focusing on coverage of candidates Fernando Haddad (PT), Jose Serra (PSDB) and Celso Russomano (PRB). The results indicate that the Folha de $S$. Paulo reinforces a trend of electoral preference exists in the city, which contradicts the hypothesis of scheduling.

KEYwords: Electoral Coverage; Quantiative Metodology; AgendaSetting.

$\mathrm{O}$ artigo apresenta a metodologia quantitativa como possibilidade para as análises do conteúdo produzido pela imprensa em períodos eleitorais desde um estudo da cobertura da Folha de S. Paulo durante a eleição municipal de 2012, em São Paulo. O objetivo desta pesquisa é observar as principais características da cobertura jornalística, tendo como pressuposto que os jornais impressos influenciam o debate público a partir do processo de agendamento ${ }^{1}$. A hipótese é de que as técnicas de análise quantitativa permitem identificar padrões distintos de tratamento aos candidatos e a caracterizar a cobertura como um todo.

A corrente teórica com mais larga difusão no Brasil considera a importância dos veículos de comunicação na construção da agenda pública, em especial dos jornais impressos, que contemplariam um poder maior de agendamento do que os meios eletrônicos (McCombs, 2009) devido às características de visibilidade e solidez (Wolf, 2001). Na mesma linha, pesquisas sobre cobertura política tentam identificar como os assuntos ganham espaço, visibilidade e são tratados nos jornais impressos ${ }^{2}$. 
O monitoramento quantitativo da produção jornalística durante o período de campanha eleitoral permite acompanhar a elaboração e discutir a qualidade da informação que os cidadãos recebem. Para tanto, as análises partem de alguns indicadores que, na pesquisa quantitativa, são as representações simplificadas dos conceitos e teorias já presentes na literatura. São essas características que, reunidas, contribuem para explicar o papel que a mídia ocupa nos períodos eleitorais e na formação da opinião sobre temas sociais e políticos. Dessa forma, o artigo apresenta uma proposta de análise quantitativa e faz um teste empírico aplicando ao estudo da cobertura feita pela Folha de S. Paulo nas eleições municipais de 2012, em São Paulo. Durante os meses de campanha eleitoral de 2012 (de julho a outubro, o que compreende 17 semanas de edições diárias do jornal), a Folha de S. Paulo publicou 1.482 textos nos quais citava pelo menos um dos candidatos à prefeitura. A unidade de análise aqui é o texto publicado e a singularidade de seleção é o nome do candidato. São consideradas características o número de citações ao longo do tempo, a localização e visibilidade dos candidatos no jornal e a valência da cobertura para os concorrentes à prefeitura.

Em 2012, a campanha para prefeitura de São Paulo não contou com candidatura à reeleição, pois Gilberto Kassab (PSD) completava seu segundo mandato consecutivo. Ao todo, foram deferidas 12 candidaturas, porém apenas três foram eleitoralmente relevantes. A candidatura de continuidade do então governo era representada por José Serra (PSDB), que passou em segundo lugar para o segundo turno, mas foi derrotado por Fernando Haddad (PT). A terceira força eleitoral ficou com Celso Russomano (PRB), que chegou a liderar a campanha no primeiro turno, mas perdeu densidade na reta final. Além desses três, também se candidataram Gabriel Chalita (PMDB), Soninha Francine (PPS), Carlos Gianazi (Psol), Paulinho da Força (PDT), Levy Fidelix (PRTB), Ana Luiza (PSTU), Miguel (PPL), Eymael (PSDC) e Anaí Caproni (PCO). 
No início da campanha, José Serra, ex-prefeito e ex-governador de São Paulo, apresentava os mais altos índices de intenção de voto, passando de $30 \%$. Ele era seguido do deputado federal e apresentador de programa de televisão Celso Russomano. Ambos muito conhecidos e presentes no imaginário do eleitoral paulistano. A grande incógnita da disputa era Fernando Haddad, ex-ministro da Educação do governo Lula, apoiado pelo governo federal e que se apresentava como principal opositor político à gestão Kassab. No entanto, como se tratava da primeira disputa eleitoral de Haddad, no início da campanha ele apresentava baixos índices de intenção de voto. Ao longo de todo o primeiro turno houve um crescimento contínuo das intenções de voto em Haddad, enquanto Serra permaneceu estável e Russomano teve crescimento até meados de setembro, quando começou a apresentar declínio.

Para verificar como o jornal tratou os candidatos com desempenhos tão distintos nas intenções de voto, o texto está dividido em três partes. Na próxima, apresentamos conceitos gerais sobre metodologia quantitativa na análise de coberturas jornalísticas e as variáveis empíricas. O tópico seguinte expõe o teste empírico da aplicação das variáveis para a cobertura da campanha eleitoral em 2012, no município de São Paulo. Por fim, são apresentadas notas conclusivas sobre os "achados" da aplicação dessa metodologia para a cobertura política.

\section{Metodologia quantitativa para análise de cobertura sobre temas políticos}

As pesquisas a que nos filiamos aqui e que analisam a produção jornalística têm como ponto de partida a teoria da agenda (McCombs; Shaw, 1972) e o papel que os meios de comunicação possuem no processo de mediação entre a esfera pública e a política (Habermas, 1984). Na medida em que a mídia veicula notícias a respeito de assuntos de interesse público, ela contribui com o debate, estabelecendo temas na agenda pública. 
As análises de conteúdo, portanto, são baseadas nesses pressupostos e uma das formas de analisar a cobertura jornalística é por meio da metodologia quantitativa, que possui instrumentos analíticos que permite identificar padrões na cobertura realizada pelos jornais.

A utilização do método quantitativo nas pesquisas sobre cobertura jornalística tem por objetivo identificar como que determinados temas aparecem nos jornais por meio de uma série de características que podem ser medidas e contabilizadas. Existem outras formas de estudar as características da produção jornalística, mas alguns fatores explicam e também justificam a utilização dessa estratégia para este tipo específico de análise que tratamos neste artigo. A definição do procedimento não depende das escolhas do pesquisador e nem do fato de um ser melhor que outro - o que ainda tem sido motivo de embate entre quantitativistas e qualitativistas -, mas sim do objeto que o indivíduo pretende estudar e dos objetivos que a pesquisa possui. Ou seja, a escolha do método está relacionada com o objeto e não com as preferências do pesquisador.

Para a utilização da metodologia quantitativa são necessárias algumas orientações, tais como a exigência de um grande número de casos para a possibilidade de detectar diferenças significativas e poder fazer inferência na realidade (Davis, 1976). Como o monitoramento das eleições reúne um número elevado de notícias, utiliza-se o método quantitativo por proporcionar a análise de grande quantidade de casos e, também, para poder identificar padrões das coberturas (Ragin, 1984).

Cada método engloba objetos, características e objetivos diferenciados, como aponta Ragin (1984), e dá às pesquisas caráter de cientificidade, pois permite explicar de que forma que os resultados foram alcançados. Isso justifica, também, a importância do procedimento estar de acordo com o tipo de objeto a ser analisado e os objetivos que se têm com a pesquisa, pois como apontam Mahoney e Goertz (2006), há contrastes 
entre o que um método e o outro podem proporcionar para as pesquisas, mesmo que esses sejam complementares.

A metodologia quantitativa também é adequada para pesquisas em que o universo de análise engloba longos períodos, como é o caso de análises comparativas de vários períodos eleitorais. $\mathrm{Na}$ análise quantitativa é possível pesquisar um grande número de indivíduos (neste caso, os textos jornalísticos), analisando muitas de suas características, pois tal método permite reduzir uma grande massa de informações em indicadores.

Pesquisas quantitativistas consideram que os fenômenos sociais podem ser explicados a partir da representação em números que permitem algumas generalizações e indicam relações de causalidade que validam ou rejeitam certas teorias (Cervi, 2009). Os métodos quantitativos permitem relacionar os dados da realidade social - neste caso, a produção que os jornalistas fazem sobre a esfera política - com teorias já existentes e observar como elas se aplicam em casos específicos. O objetivo é identificar como os conceitos se aplicam em realidades específicas com o objetivo de caracterizar como se dá a cobertura jornalística sobre o assunto e não para tentar, por meio de um caso, refutar teorias gerais.

A pesquisa empírica, utilizando variáveis quantitativas e qualitativas, não está distante dos estudos teóricos. As variáveis são indicadores que representam as características dos textos analisados, ou seja, cada variável analisada num determinado texto é uma caracterização que o pesquisador faz de acordo com conceitos já existentes na literatura. Dessa forma, as variáveis são criadas a partir de conceitos teóricos. Nas análises quantitativas, os conceitos são transformados em variáveis, pois para poder identificar como eles estão presentes no mundo real é necessário encontrar uma forma de operacionalizar tais características. Os conceitos, por si só, não podem ser encontrados na realidade social, ou seja, 
é preciso algo que os defina e que possa ser identificado com clareza nos objetos analisados.

O processo de coletas de evidências, na realidade parte sempre de ideias e conceitos resultantes de outros estudos, e que por meio de técnicas, podem ser medidas e contadas em objetos específicos (Cervi, 2009). Dessa forma, tenta-se compreender como as variáveis utilizadas na coleta de dados representam os conceitos teóricos já existentes e de que maneira, quando correlacionadas, podem contribuir para explicar a produção que os periódicos fazem sobre temas políticos.

Para a análise apresentada neste artigo trabalha-se com as seguintes variáveis 3 : quantidade de citações, índice de visibilidade (composto por formato, número da página, tamanho, posição na página) e valência. A primeira delas - número de citações dos candidatos - é identificada com o objetivo de saber quais candidatos apareceram mais na cobertura durante os três meses de campanha eleitoral. O número de entradas sobre determinado candidato, por exemplo, é o primeiro passo para identificar o tipo de cobertura realizada pelos veículos sobre as eleições. A identificação da quantidade de textos com citações de candidatos está relacionada com a Teoria do Gatekeeping, que considera que os assuntos passam por diversos gates. Segundo Shoemaker e Vos (2009), os assuntos são escolhidos de acordo com interesses organizacionais, políticos, econômicos e sociais.

Reunindo quatro variáveis - tamanho, posição, número da página e formato cria-se o índice de visibilidade,que nada mais é do que uma variável composta que representa o agregado de distintas dimensões de um mesmo objeto de análise. Em formato das entradas, categorizam-se as entradas desde "entrada de primeira página", que possui a maior visibilidade, até "coluna do leitor" e "editorial", que representam formatos de menor visibilidade. Segundo Ferreira Júnior (2002), a capa é a expressão imagética que impacta o leitor e os temas 
presentes nesse espaço são considerados relevantes para chamar a atenção para o jornal.

A variável espaço é a soma dos centímetros quadrados que os textos ocupam no jornal. O objetivo dessa medição é identificar como os temas ganham espaço no jornal. Determinados assuntos podem ter um número grande de entradas, mas como aparece sempre no formato de nota, ocupa pouco espaço e assim terá menos chances de ser lido se comparado com uma reportagem que ocupa a parte superior da página. Outro assunto pode ter um número menor de entradas, mas como aparece sempre em reportagens, ocupa mais espaço no jornal e ganham mais atenção dos leitores. Essas relações mostram que vários indicadores contribuem para explicar a visibilidade de um tema. A possibilidade de medir o espaço permite posteriormente identificar o total de espaço que cada assunto ou candidato ocupou com relação aos demais, assim como identificar o tamanho médio dos textos e suas variações. Esse indicador pode ser usado também para categorizar os textos em grande, médio e pequeno, a através da Fórmula de Sturges ${ }^{4}$, o que permite identificar mais especificadamente o tamanho dos textos, transformando uma variável contínua em categórica, possibilitando posteriormente a comparação entre tamanho e temas. Essa variável nova é usada no conjunto de indicadores para a criação do índice de visibilidade.

Para o índice de visibilidade observa-se também a numeração da página, partindo-se do pressuposto de que os leitores tendem a ler as páginas iniciais do jornal. Segundo Weaver, McCombs e Spellman (1975), é a forma de valorização dos temas pelos jornais, através da sua localização em termos de paginação, que define grande parte do impacto no debate. As matérias de primeira página têm duas vezes mais leitura do que as que aparecem em suas páginas internas (McCombs, 2009). Ao abrir os jornais, os leitores tendem a direcionar a leitura para as páginas do lado direito, por isso que as entradas presentes neste espaço possuem mais visibilidade. O mesmo também se dá quando 
a variável identifica os cadernos em que os textos se encontram, pois as páginas do primeiro caderno têm visibilidade maior que as dos outros cadernos.

Outra variável que também ajuda a compreender a visibilidade que o assunto recebe é a posição do texto na página do jornal (tanto nos quadrantes quanto nas dobras). A localização da notícia nos quadrantes está relacionada com as zonas de visualização, já que intuitivamente estamos condicionados a fixar a visão na direção da esquerda para a direita, sendo que a leitura dos jornais segue esta mesma lógica (Silva, 1985). peso que cada quadrante possui está baseado no método de leitura ocidental, sendo que a posição de um texto indica se ele tem potencial para ser lido por um número maior ou menor de pessoas (Cervi, 2003).

Além desses indicadores, as pesquisas sobre acompanhamento das eleições utilizam uma variável específica para medir a tendenciosidade dos veículos para com determinados candidatos. Para observar como eles aparecem nos textos, são analisados de acordo com a valência. Categorizada em positiva, negativa, neutra e equilibrada, a valência propõe a discussão sobre o papel do jornal na formação da imagem. Desta forma, o principal critério para identificar a valência da matéria em relação a cada candidato procura esclarecer se o texto beneficia ou prejudica sua candidatura. Classificam-se as valências de acordo com o efeito potencial para cada um dos candidatos citados no texto, notando-se ou não intenção de viés ou parcialidade jornalística, segundo a proposta do DOXA (Laboratório de Pesquisa em Comunicação Política e Opinião Pública). Segundo Aldé (2003), classificar se as matérias são favoráveis ou prejudiciais aos candidatos e suas campanhas, mesmo sem uma intencionalidade aparente por parte do veículo de comunicação, permitenos identificar que mesmo pretendendo a objetividade, o próprio processo de pautar o noticiário e a decisão de veicular determinadas notícias já representa um processo de escolha política. Destaca-se que em alguns momentos o próprio fato noticiado 
torna-se impreterivelmente negativo para determinado candidato, no entanto, em outros momentos indicam as tendências editoriais e de modo mais ou menos explícito as preferências políticas dos veículos.

\section{Um teste empírico: aplicação da metodologia para a eleição de 2012, em São Paulo}

A cobertura feita pela Folha de S. Paulo sobre a eleição municipal de 2012, em São Paulo, contou com 1.428 textos ou imagens contendo a citação de pelo menos um dos candidatos à prefeitura, entre julho e outubro daquele ano - período que compreende o primeiro e segundo turno. Isso representa uma média diária de 12 citações de candidatos por dia. A primeira questão em termos quantitativos é que essa distribuição das inserções na cobertura eleitoral não foi equilibrada ao longo do período. Ao contrário, há um crescente número de citações conforme se aproxima a data da eleição. Esse efeito de "acúmulo" de cobertura nas últimas semanas da disputa, já foi demonstrado pela literatura e serve para indicar o padrão de cobertura factual, pautada apenas nos acontecimentos cotidianos das campanhas. Assim, quanto mais se aproxima o dia da eleição, mais fatos são produzidos pelas candidaturas, maior a atenção e interesse dos eleitores e, por consequência, cresce o número de citações dos candidatos nos jornais.

O Gráfico 1, a seguir, mostra a distribuição das citações de candidatos à prefeitura de São Paulo pela Folha de S. Paulo, por mês. Percebe-se que a cobertura do segundo turno, que fica restrita ao mês de outubro, representa quase metade de todas as citações da cobertura (43,14\%). Na outra ponta, no primeiro mês da corrida eleitoral, foram feitas apenas 203 citações de concorrentes, representando 14,22\%. Em agosto, a cobertura manteve-se estável, com 218 citações $(15,27 \%)$, para dar um salto em setembro, mais próximo do primeiro turno, com 391 citações no total, ou 27,38\%. 
Vale ressaltar ainda que, o fato da cobertura se concentrar principalmente no segundo turno, quando apenas os dois mais votados continuam na disputa, nos permite concluir que ela ficou muito concentrada nas candidaturas de Fernando Haddad (PT) e José Serra (PSDB). Ou seja, a concentração da cobertura no segundo turno ou nas semanas que antecedem a votação mostra uma tendência de concentração nas candidaturas consolidadas, com maiores chances de vitória - indicadas pelas pesquisas de intenção e voto - e não uma cobertura plural, que dê visibilidade à proposta ou campanhas alternativas. Trata-se de um padrão de cobertura que reforça as tendências de intenção de voto já presentes na sociedade e não atua como propagador de visões distintas, que ofereçam subsídios para o eleitor comparar as alternativas existentes.

$$
\begin{aligned}
& \text { Gráfico } 1 \text { - Distribuição das } \\
& \text { citações dos candidatos }
\end{aligned}
$$

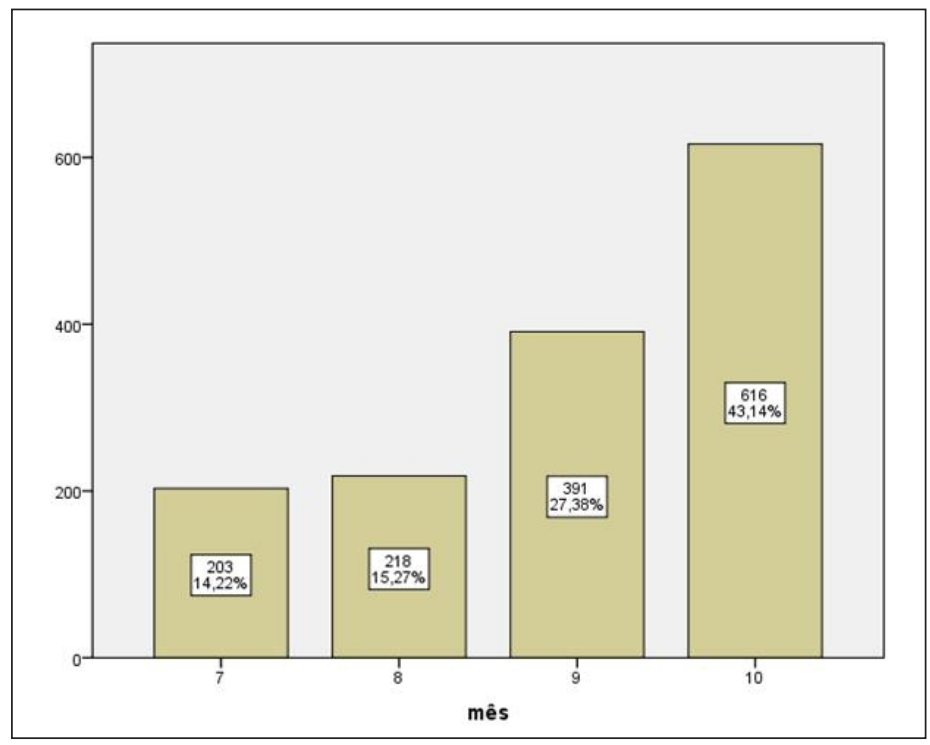

Fonte: Grupo de Pesquisa em Mídia, Política e Atores Sociais (UEPG/UFPR). 
As diferenças nos totais de citações dos candidatos durante a campanha eleitoral, indicadas, abaixo, no Gráfico 2 (separadas entre citações no primeiro turno e citações em toda a campanha), reforçam a ideia de concentração da cobertura nos principais concorrentes. Enquanto Haddad e Serra ficam acima de 850 citações, no total, o terceiro colocado, Celso Russomano (PRB), fica em terceiro lugar, com menos de 500 citações, ou seja, aproximadamente $40 \%$ a menos de citações que os demais concorrentes.

Depois de Russomano, os quatro outros candidatos apresentam números de citações que chegam ao máximo de $20 \%$ das aparições de Haddad e Serra. Portanto, no que diz respeito à cobertura geral, há um padrão de citações dividido em três grupos distinto. Os mais citados: Haddad e Serra; um intermediário, representado por Russomano; e o grupo dos menos citados, formado pelos demais concorrentes.

Gráfico 2 - Diferença no número de citações durante a campanha

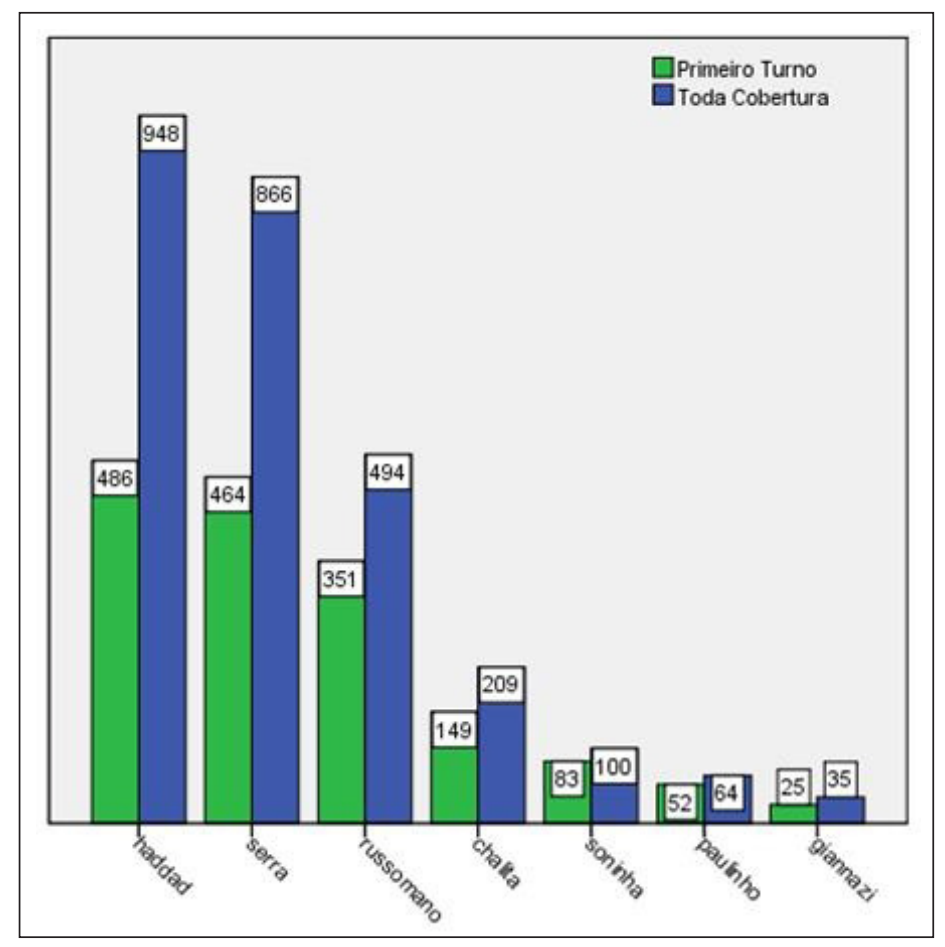

Fonte: Grupo de Pesquisa em Mídia, Política e Atores Sociais (UEPG/UFPR). 
Se considerarmos apenas o primeiro turno, quando todos os candidatos estavam na disputa, percebe-se uma aproximação no número de citações entre os três principais concorrentes. A diferença entre Russomano e os dois primeiros diminui, criando um padrão distinto do anterior, com apenas dois grupos: os mais citados (Haddad, Serra e Russomano) e os demais recebem menos de $1 / 3$ do total de citações dos anteriores. Além de reforçar a ideia de cobertura eleitoral pouco democratizante, no sentido de não oferecer visibilidade às candidaturas alternativas, o jornal parece reforçar as tendências indicadas pelas pesquisas de intenção de voto e não ao contrário. Ou seja, esses números permitem sustentar a hipótese de que, ao invés de um agendamento da imagem dos candidatos pelos jornais para o eleitor, o que acontece é um agendamento inverso - a partir das intenções de voto dos eleitores para as decisões editoriais do jornal.

Ao separarmos os dados sobre citação dos candidatos na Folha de S. Paulo por semana, da campanha eleitoral, percebemos algumas variações que não podem ser notadas a partir dos grandes números, apresentados anteriormente. Aqui, serão apresentadas informações apenas sobre os três candidatos com maior número de citações, visto que os demais tiveram aparição residual no periódico. A Tabela 1, a seguir, mostra os resultados dos testes de diferença de médias (Anova) para as aparições por mês. O conteúdo serve para indicar se houve mudança significativa no número de citações dos concorrentes entre cada um dos meses analisados. Na tabela, foram mantidos apenas os resultados considerados estatisticamente significativos, ou seja, aqueles que indicam uma mudança significativa no número de citações dos candidatos de um mês para outro. O que se quer saber com este teste é se determinado candidato apresentou uma diferença significativa no número de citações entre dois períodos distintos. Aqui, no caso, entre dois meses. O comportamento de Serra e Haddad é muito semelhante no jornal. Ambos apresentam diferença significativa e 
positiva apenas entre os meses de agosto e setembro. Como as alterações médias são positivas (0,084 para Serra e 0,083 para Haddad), houve crescimento no número de citações de ambos em setembro, quando comparado a agosto. Nos demais meses as diferenças não foram significativas.

Tabela 1 - Presença dos candidatos nos meses de campanha

\begin{tabular}{lcccc}
\hline \multicolumn{1}{c}{ Candidato } & (I) mês & (J) mês & Diferença média (I-J) & Sig. \\
Serra & Agosto & Setembro & $0,084^{*}$ & 0,028 \\
Haddad & Agosto & Setembro & $0,083^{*}$ & 0,034 \\
Russomano & Outubro & Agosto & $-0,075^{*}$ & 0,005 \\
& & Setembro & $-0,102^{*}$ & 0,000 \\
\hline
\end{tabular}

* Significativo a 0,05.

Fonte: Grupo de Pesquisa em Mídia, Política e Atores Sociais (UEPG).

Como era de se esperar, no caso de Russomano as diferenças significativas ficaram em outubro, visto que ele não passou para o segundo turno. Em relação a outubro, Russomano teve mais citações no mês de agosto e setembro, dado que os sinais das diferenças são negativos (-0,075 para agosto e -0,102 para setembro). O Gráfico 3 ilustra as diferenças no número de aparições dos candidatos por semana e mês, além de mostrar a dinâmica das distâncias entre eles.

Em primeiro lugar, o Gráfico 3 deixa claro como há um padrão geral de citações de candidatos em julho/agosto em relação aos meses de setembro/outubro. Os dois primeiros têm um número menor para os três concorrentes analisados aqui. Percebe-se um salto no mês de setembro. Enquanto em julho/agosto as citações semanais dos candidatos ficavam abaixo de 100, em setembro elas passam de 150 e em outubro, para os dois que chegam ao segundo turno, giram em torno de 200 citações semanais. Outra 
diferença entre os períodos analisados aqui diz respeito à distância entre Russomano e os demais. Em julho, Russomano aparece abaixo dos outros, todas as semanas. Serra é o mais citado em duas semanas (2 e 4) e Serra e Haddad ficam empatados no número de citações nas semanas 1 e 3 . Em agosto as diferenças entre os três candidatos são bem menores, com algumas semanas apresentando mudanças nas posições deles. $\mathrm{Na} 5^{\underline{a}}$ semana, Russomano fica em segundo, sendo mais citado que Serra. Na 6 ${ }^{\mathrm{a}}$, o mais citado é Haddad, com diferença pequena. Já na 7ª , $8^{\underline{a}}$ e $9^{\underline{a}}$ Serra fica na dianteira. Em setembro há um crescimento no número de citações de todos eles, portanto as distâncias continuam curtas e as pequenas variações indicam quem foi mais citado em cada semana. No final de setembro (semanas $12^{\underline{a}}$ e $13^{\underline{a}}$ ), Russomano é o mais citado entre os candidatos.

Gráfico 3 - Diferença no número de citações durante a campanha

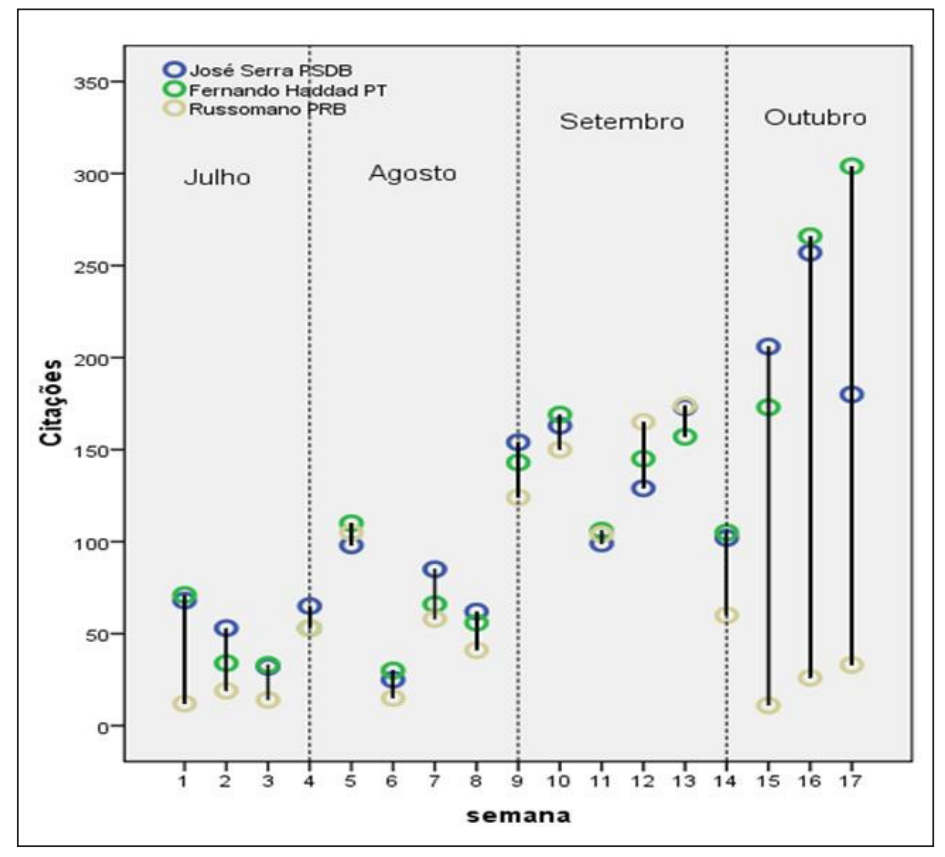

Fonte: Grupo de Pesquisa em Mídia, Política e Atores Sociais (UEPG/UFPR). 
Em outubro, já no segundo turno, há uma brusca queda de Russomano, como era de se esperar, voltando aos níveis de citações de julho. A primeira semana de outubro marca um empate entre Serra e Haddad. Serra é o mais citado na primeira semana de outubro, mas depois é ultrapassado gradativamente por Haddad. Na última semana de cobertura do segundo turno, Haddad já está bem à frente de Serra em número de citações.

Até aqui, a descrição da cobertura feita pela Folha de S. Paulo da campanha para prefeito de São Paulo, em 2012, nos permite dizer que houve uma média de 12 citações de candidatos, por dia. Porém, essa média é pouco representativa, pois a cobertura concentrou-se principalmente nos meses de setembro e outubro, cabendo ao segundo turno quase metade do total de citações de toda a campanha. Isso nos leva à segunda constatação: a cobertura eleitoral ficou centrada nos principais candidatos, não dando espaço aos demais concorrentes. No primeiro turno, Haddad e Serra ficaram à frente dos demais, seguidos por Russomano (que ganhou maior visibilidade em setembro). Já, no segundo turno, Haddad teve número maior de citações do que Serra nas páginas da Folha de S. Paulo.

No entanto, analisar apenas o número de citações não é suficiente para entender o padrão de cobertura dado aos candidatos pelo jornal, visto que dependendo do formato do texto, do tamanho, do número da página e da posição na mesma, um texto tem maiores ou menores chances de ser lido. Portanto, além da quantidade de citações, a análise da presença dos concorrentes no jornal depende também da "qualidade" dessas citações. Para uma análise dos diferentes níveis de visibilidade dos textos no jornal, propomos a criação de um índice, chamado de Índice de Visibilidade, que reúne informações sobre diferentes dimensões de visibilidade de um texto no jornal. $O$ índice é composto por quatro variáveis isoladas, que, juntas, identificam se determinado texto tem alta, média ou baixa visibilidade no jornal ${ }^{5}$. A partir daí é possível verificar se 
determinado candidato tende a aparecer mais em textos de alta ou baixa visibilidade. A Tabela 2, a seguir, sumariza os totais por tipo de visibilidade nos quatros meses de campanha em 2012.

Tabela 2 - Distribuição da visibilidade dos textos sobre campanha eleitoral

\begin{tabular}{lcc}
\hline & Frequência & Percentual \\
Baixa & 784 & 54,9 \\
Média & 528 & 37,0 \\
Alta & 116 & 8,1 \\
Total & 1428 & 100,0 \\
\hline
\end{tabular}

Fonte: Grupo de Pesquisa em Mídia, Política e Atores Sociais (UEPG).

Percebe-se que os textos que citaram os candidatos à prefeitura tenderam a apresentar baixa visibilidade (54,9\%), seguidos de média visibilidade (37,0\%). Menos de $10 \%$ do total da cobertura eleitoral apresentou alta visibilidade na Folha de SP. A análise ao longo do tempo para os tipos de visibilidade também não mostra grandes diferenças. A partir do gráfico abaixo é possível perceber que o número de textos com alta visibilidade sempre é menor, apresentando um lento e gradual crescimento conforme se aproxima o segundo turno. A visibilidade baixa apresenta o maior número de textos em praticamente todas as semanas. Exceção feita à semana 14, na transição do primeiro para segundo turno, quando a visibilidade média tem número maior de textos que a baixa. Por fim, também é possível perceber que o crescimento visto nas análises anteriores no volume de citações dos candidatos ao longo do tempo é explicado pelo maior número de textos com baixa visibilidade, ou seja, existe um aumento quantitativo da presença dos candidatos nas páginas dos jornais conforme a campanha 
se aproxima do fim, porém não há uma melhora na qualidade da visibilidade. Os candidatos aparecem mais, porém em textos pequenos e em formatos e páginas pouco lidas conforme mostra o Gráfico 4.

Gráfico 4 - Crescimento da visibilidade dos candidatos ao longo do tempo

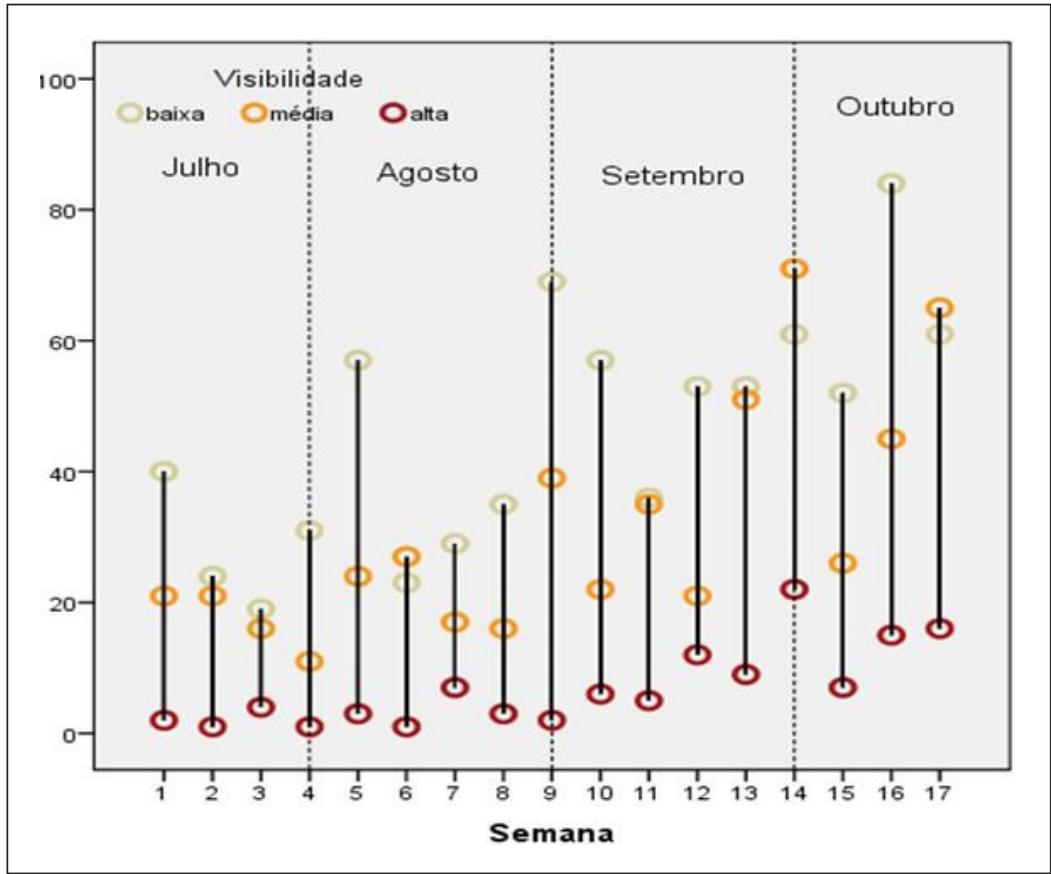

Fonte: Grupo de Pesquisa em Mídia, Política e Atores Sociais (UEPG/UFPR).

Agora que já sabemos que a distribuição das visibilidades dos textos de cobertura eleitoral na Folha de S. Paulo não é proporcional, é preciso identificar se há predomínio de algum candidato em visibilidades mais altas. Se houver, isso significa que 
determinado candidato, ainda que em menor número de citações, apareceu em espaços que permitem maior visibilidade. A Tabela 3 mostra a distribuição percentual das citações dos três principais candidatos por tipo de visibilidade. Na média, em torno de $45 \%$ das citações deles foram de baixa visibilidade, cerca de $40 \%$ de média visibilidade e pouco menos de $15 \%$ de alta visibilidade. No agregado, isso demonstra que os três principais candidatos, juntos, apresentaram uma visibilidade maior que o total da cobertura, quando comparado com os percentuais da Tabela 2. A comparação desses dois grupos de percentuais nos permite inferir que além de terem menos quantidade de cobertura, os demais concorrentes foram os que mais contribuíram para as entradas de baixa visibilidade, portanto concentrando-se em espaços e formatos menos lidos, além de citados em número bem menor de vezes.

Tabela 3 - Índice de visibilidade para os três principais candidatos

\begin{tabular}{|c|c|c|c|c|c|c|c|c|}
\hline \multirow{2}{*}{ Candidato } & \multicolumn{8}{|c|}{ Índice de visibilidade } \\
\hline & \multicolumn{2}{|c|}{ Baixa } & \multicolumn{2}{|c|}{ Média } & \multicolumn{2}{|c|}{ Alta } & \multicolumn{2}{|c|}{ Total } \\
\hline Serra & 422 & $48,7 \%$ & 352 & $40,6 \%$ & 92 & $10,6 \%$ & 866 & $100,0 \%$ \\
\hline Haddad & 462 & $48,7 \%$ & 381 & $40,2 \%$ & 105 & $11,1 \%$ & 948 & $100,0 \%$ \\
\hline Russomano & 216 & $43,7 \%$ & 224 & $45,3 \%$ & 54 & $10,9 \%$ & 494 & $100,0 \%$ \\
\hline
\end{tabular}

Fonte: Grupo de Pesquisa em Mídia, Política e Atores Sociais (UEPG).

Agora, em uma comparação entre as distribuições percentuais dos três candidatos, percebe-se que Haddad e Serra apresentam exatamente os mesmos percentuais de textos com baixa visibilidade (48,7\%), enquanto Russomano fica um pouco abaixo, com $43,7 \%$. Serra e Haddad voltam a empatar em termos de visibilidade média, em torno de $40 \%$, com Russomano ficando um pouco à frente $(45,3 \%)$. Já em relação à alta 
visibilidade, Haddad apresenta $11 \%$ do total de citações nessa categoria, contra $10 \%$ de Serra e Russomano. Com isso, é possível afirmar que, além de ter mais citações que Serra na cobertura eleitoral da Folha de S. Paulo, Haddad também esteve presente em espaços de maior visibilidade do que seu adversário - ainda que as diferenças sejam pequenas e estatisticamente não significativas.

Para concluir as análises sobre o tratamento dispensado pelo jornal aos candidatos à prefeitura, propomos agregar às variáveis quantidade de citações e visibilidade, a valência dos textos. Cada texto jornalístico, em função da maneira como é construído e dos termos utilizados pelo autor, pode ter uma valência positiva, negativa, neutra ou equilibrada para o candidato ${ }^{6}$. Para verificar a existência de diferenças estatisticamente significativas na presença dos candidatos em textos com valência positiva e por índice de visibilidade serão usados dois tipos de testes. Os resíduos padronizados mostram o tipo de relação entre cada categoria das duas variáveis (presença do candidato $\times$ visibilidade do texto). Se o resíduo padronizado for maior que $\pm 2,0$ significa que há resíduos acima da expectativa para aquela categoria. Por exemplo, na Tabela 4, o resíduo padronizado de 2,0 para presença de Serra (coluna sim) em textos com visibilidade média indica que é possível encontrar mais textos com valência positiva de Serra em visibilidade média do que nas demais categorias. O segundo teste é a diferença de médias qui-quadrado (sig.), que indica se as diferenças são estatisticamente significativas ou não. Se o sig. ficar abaixo de 0,050, significa que há diferenças significativas entre as duas variáveis, portanto a relação entre uma ou mais categorias apresentará resíduos acima de $\pm 2,0$.

A tabela a seguir, com os resultados para a relação entre valências positivas dos candidatos por tipo de visibilidade, indica que a relação mais forte é para Haddad com coeficiente de sig. de 17,821 (0,000), indicando que as valências positivas do candidato do PT tenderam a se concentrar em um tipo de visibilidade. Olhando para os resíduos 
padronizados, percebe-se claramente que os resíduos são $+2,3$ para visibilidade alta, $+2,0$ para visibilidade média e $-2,5$ para visibilidade baixa. Ou seja, texto positivo de Haddad tende a aparecer em espaços de visibilidade alta e média e a não estarem em textos com baixa visibilidade.

Tabela 4 - Relação entre valência positiva e visibilidade dos candidatos

\begin{tabular}{|c|c|c|c|c|c|c|c|}
\hline \multirow{2}{*}{\multicolumn{2}{|c|}{$\begin{array}{l}\text { Resíduos Padronizados } \\
\text { Valência Positiva }\end{array}$}} & \multicolumn{2}{|c|}{ Serra } & \multicolumn{2}{|c|}{ Haddad } & \multicolumn{2}{|c|}{ Russomano } \\
\hline & & Não & Sim & Não & Sim & Não & Sim \\
\hline \multirow{3}{*}{ Índice de Visibilidade } & Baixa & 0,5 & $-1,7$ & 0,9 & $-2,5$ & 0,1 & $-0,5$ \\
\hline & Média & $-0,6$ & 2,0 & $-0,7$ & 2,0 & $-0,1$ & 0,6 \\
\hline & Alta & 0,0 & 0,2 & $-0,8$ & 2,3 & 0,0 & 0,2 \\
\hline \multicolumn{2}{|l|}{ Qui-quadrado (sig.) } & \multicolumn{2}{|c|}{$7,145(0,028)$} & \multicolumn{2}{|c|}{$17,821(0,000)$} & \multicolumn{2}{|c|}{$0,697(0,706)$} \\
\hline
\end{tabular}

Fonte: Grupo de Pesquisa em Mídia, Política e Atores Sociais (UEPG).

No caso de Serra, o coeficiente sig. também é significativo $(7,145)$, embora não tão forte quanto o de Haddad. Os resíduos mostram que valências positivas de Serra tendem a estar em textos com visibilidade média $(+2,0)$. Para o candidato Russomano não é possível indicar tendência de concentração de valências positivas por tipo de visibilidade, visto que o coeficiente sig. fica em 0,697, com nível de significância de 0,706. A partir dos dados acima, é possível afirmar que em relação à valência positiva, Haddad foi o maior beneficiado, pois teve mais visibilidade alta para esse tipo de texto.

Aplicando o mesmo teste para a valência negativa (Tab. 05), percebe-se que o maior coeficiente de sig. é o de Serra, com 10,130 (0,006). Olhando para os resíduos, percebe-se que textos com valência negativa para Serra tendem a não aparecer em espaço 
de baixa visibilidade $(-2,0)$ e estão concentrados em visibilidade média $(1,9)$. No caso de Russomano, o coeficiente de sig. fica em 6,282 (0,043), sendo estatisticamente significativo. Textos negativos de Russomano tendem a estar em espaços com visibilidade média e a não estar em visibilidade baixa.

Tabela 5 - Relação entre valência negativa e visibilidade dos candidatos

\begin{tabular}{|c|c|c|c|c|c|c|c|}
\hline \multirow{2}{*}{\multicolumn{2}{|c|}{$\begin{array}{l}\text { Resíduos Padronizados } \\
\text { Valência Negativa }\end{array}$}} & \multicolumn{2}{|c|}{ Serra } & \multicolumn{2}{|c|}{ Haddad } & \multicolumn{2}{|c|}{ Russomano } \\
\hline & & Não & Sim & Não & Sim & Não & Sim \\
\hline \multirow{3}{*}{ Índice de Visibilidade } & Baixa & 0,7 & $-2,0$ & 0,4 & $-1,2$ & 0,3 & $-1,4$ \\
\hline & Média & $-0,7$ & 1,9 & $-0,6$ & 1,8 & $-0,4$ & 1,9 \\
\hline & Alta & $-0,4$ & 1,1 & 0,3 & $-0,9$ & 0,1 & $-0,6$ \\
\hline \multicolumn{2}{|l|}{ Qui-quadrado (sig.) } & \multicolumn{2}{|c|}{$10,130(0,006)$} & \multicolumn{2}{|c|}{$6,006(0,050)$} & \multicolumn{2}{|c|}{$6,282(0,043)$} \\
\hline
\end{tabular}

Fonte: Grupo de Pesquisa em Mídia, Política e Atores Sociais (UEPG).

Haddad é o candidato que apresenta as valências negativas menos concentradas em um tipo de visibilidade, ficando com sig. de 6,006 (0,050). Ele tende a ter valência negativa em média visibilidade e a não ter negativo nas categorias baixa e alta.

Se compararmos os sinais dos resíduos, perceberemos que, para as valências positivas, os resíduos são negativos para os três candidatos na visibilidade baixa e positivos para as outras duas categorias. Já no caso das valências negativas, os resíduos são negativos para baixa visibilidade nos três candidatos, porém na visibilidade alta existem resíduos positivos apenas para Serra. Haddad e Russomano têm resíduos negativos nessa categoria. 


\section{Considerações finais}

O artigo teve por finalidade apresentar a metodologia quantitativa como uma ferramenta para análise de jornais impressos e que tem como objetivo identificar a cobertura da imprensa durante períodos eleitorais. Para exemplificar a aplicação dessa metodologia, apresenta-se uma análise da cobertura das eleições municipais, de São Paulo, em 2012, na Folha de S. Paulo. A pesquisa parte da importância que os veículos de comunicação possuem no debate público como mediadores das informações entre a esfera pública e o poder político. A partir da metodologia quantitativa de análise de conteúdo é possível dar, por meio de alguns indicadores, atenção aos aspectos da produção dos jornais neste caso, a Folha de S. Paulo - que podem responder a pergunta de pesquisa: Como foi a cobertura eleitoral de 2012 sobre os candidatos à prefeitura de São Paulo?

Do ponto de vista empírico, foi possível aferir os principais aspectos do padrão de cobertura da Folha de S. Paulo. Em primeiro lugar, não se trata de uma cobertura equilibrada ao longo de todo o período, pois depende dos fatos produzidos pelas campanhas, fatos estes que se multiplicam conforme se aproxima o dia da votação. Por consequência, há um crescimento quase constante do volume de cobertura ao longo do tempo. Uma segunda característica da cobertura geral é que ela se concentra nos candidatos de maior expressão, não dando espaço equivalente ou minimamente proporcional à grande maioria dos concorrentes de partidos nanicos. A cobertura concentrou-se em Haddad, Serra e Russomano. Com isso, é possível afirmar que o jornal não contribui para a pluralização do debate público a respeito da disputa eleitoral, pois além de depender das agendas dos candidatos, concentra sua atenção apenas naqueles que já têm projeção na memória do eleitorado ou contam com partidos políticos estruturados e fortes redes de apoios sociais.

A respeito da cobertura dos principais candidatos, pode-se perceber um favorecimento ao candidato do PT, que teve um número maior de entradas no jornal 
que os demais candidatos (948). José Serra ficou um pouco atrás de Haddad, com 866 citações no jornal, considerando os dois turnos da disputa. Além disso, Haddad apareceu mais em textos de média e alta visibilidade do que José Serra. Por fim, as entradas com valência positiva de Haddad tenderam a estar em espaços de maior visibilidade do que as de Serra, enquanto a valência negativa de Serra predominou em espaços de média visibilidade.

As análises a partir de um estudo de caso não nos permitem generalizar as conclusões para demais veículos de comunicação. Para tanto, seria necessário replicar a metodologia utilizada aqui em outros jornais e/ou disputas eleitorais. O objetivo aqui foi demonstrar as potencialidades e limitações do uso dos métodos quantitativos na análise de conteúdo jornalístico em meios tradicionais. Para tanto, fizemos um teste empírico sobre a cobertura da Folha de S. Paulo nas eleições municipais de 2012. Espera-se que outros trabalhos na linha de análises empíricas da produção jornalística sejam produzidos para que as conclusões possam ser comparadas com o que apresentamos aqui.

\section{REFERÊNCIAS}

ARRUGUETE, Natália. Los medios de comunicación y la formación de la agenda pública. Verso e Reverso, São Leopoldo, n. 41, ano XIX, 2005/2.

BAUER, Martin. Análise de conteúdo clássica: uma revisão. In: BAUER, Martin; GASKELL, George. (Org.). Pesquisa qualitativa com texto, imagem e som: um manual prático. Petrópolis: Vozes, 2002.

CERVI, Emerson. Métodos quantitativos nas ciências sociais: uma abordagem alternativa ao fetichismo dos números e ao debate com qualitativas. In: Ayres, J. B. (Org.). Pesquisa Social: reflexões teóricas e metodológicas. Ponta Grossa: Toda Palavra Editora, 2009.

COLLING, Leandro.Agenda-setting e framing: reafirmando os efeitos limitados. Revista Famecos, Porto Alegre, v. 1, n. 14, pp. 88-101, abr. 2001.

DAVIS, James. Levantamento de Dados em Sociologia: uma análise estatística elementar. Rio de Janeiro: Zahar Editores, 1976. 
DOXA. Laboratório de Pesquisa em Comunicação Política e Opinião Pública. Disponível em: <http://doxa. iesp.uerj.br>. Acesso em: 29 out. 2013.

JUNIOR, José Ferreira. Capas de Jornal: a primeira imagem e o espaço gráfico visual. São Paulo: Senac, 2002. HABERMAS, Jünger. Political Communication in mídia Society: Does Democracy still enjoy na epistemic dimension? The impact of Normative Theory on Empirical Research. Communication Teori, n. 16, pp. 411-426, 2006.

MAIA, Rousiley. Mídia e deliberação pública: mediações possíveis. In: XII Compós, Recife, 2003. Anais do XII Encontro Anual da Compós. Recife, 2003.

McCOMBS, Maxwell; SHAW, Donald. The Agenda-Setting Function of Mass Media. Public Opinion Quarterly 36, pp. 176-187, 1972.

McCOMBS, Maxwell. New frontiers in agenda setting: Agendas of attributes and frames. Mass Comm Review, n. 24, pp. 32-52, 1997.

MIRRALES, Ana Maria. Periodismo, opinión pública y agenda ciudadana. Bogotá: Norma, 2004.

NOËLLE-NEUMANN, Elisabeth. La espiral del silencio. Barcelona: Opinión Pública, 1995.

SHOEMAKER, Pamela; VOS, Tim. Gatekeeping Theory. New York: Routledge, 2009.

SILVA, Gislene. Para pensar critérios de noticiabilidade. Revista Estudos em Jornalismo e Mídia: Florianópolis, v. 2, n. 1, pp. 95-107, 2005.

SILVA, Rafael. Diagramação: o planejamento visual gráfico na comunicação impressa. São Paulo: Summus, 1985.

WOLF, Mauro. Teorias da Comunicação: Mass Media: contextos e paradigmas, novas tendências, efeitos a longo prazo, o newsmaking. 6. ed. Lisboa: Presença, 2001.

\section{NOTAS}

1 O processo de agendamento abordado neste texto se refere à hipótese da agenda setting (McCombs e Shaw, 1972), em que os meios de comunicação teriam o poder de agendar os temas a serem discutidos na sociedade.

2 O grupo de pesquisa em Mídia, Política e Atores Sociais da Universidade Estadual de Ponta Grossa e de Comunicação Política \& Opinião Pública da Universidade Federal do Paraná realizam o monitoramento da cobertura eleitoral desde 2002 em jornais nacionais, regionais e locais. Dentre eles se destacam a Folha de S. Paulo, o Estado de São Paulo, a Gazeta do Povo, o Estado do Paraná e jornais regionais do interior do estado como Folha de Londrina, Diário dos Campos e Jornal da Manhã.

3 As pesquisas que fazem monitoramento da cobertura eleitoral possuem um conjunto maior de variáveis que representam conceitos teóricos, no entanto, aqui se discute somente aquelas utilizadas na análise apresentada. 
4 Por meio da Fórmula de Sturges é possível categorizar a variável espaço, tendo como ponto de partida a não variância da amplitude entre as classes.

5 As variáveis que compõem o índice são as seguintes: i) formato: alta visibilidade para chamada de primeira página, média visibilidade para reportagens, charges, fotos, ilustrações e colunas assinadas, baixa visibilidade para artigo assinado, editorial e carta do leitor; ii) Posição na página: alta visibilidade para página inteira, média visibilidade para meia página e baixa visibilidade para quadrante de página; iii) número da página: alta visibilidade para primeira página; média visibilidade para páginas ímpares e baixa visibilidade para páginas pares; e iv) Tamanho do texto: a partir de uma divisão em três grupos iguais, definiu-se que textos com alta visibilidade têm mais que $222,8 \mathrm{~cm}^{2}$, média visibilidade entre $56,1 \mathrm{~cm}^{2}$ e $222,7 \mathrm{~cm}^{2}$ e baixa visibilidade para textos com menos de $56 \mathrm{~cm}^{2}$ de tamanho. Por se tratar de um índice aditivo, a soma dos códigos de cada categoria define a posição que o texto estará no índice agregado. Por exemplo, um texto com alta visibilidade deve ser chamada de primeira página, em meia página e acima de $222,7 \mathrm{~cm}^{2}$. Já um texto com baixa visibilidade tem menos de $56 \mathrm{~cm}^{2}$, encontra-se em um quadrante de página par e é um artigo assinado.

6 Entende-se por valência positiva textos que fazemmenção a alguma característica do candidato usando termos positivos que indiquem força, competência, coragem, etc. As valências negativas ocorrem quando são expressos valores negativos em relação ao candidato. Valência neutra está presente em textos onde não há juízo de valor a respeito do candidato, apenas informações factuais, como agenda de campanha, etc. Valência equilibrada para os casos em que há conotação positiva e negativa no mesmo texto. A variável Valência utilizada aqui é uma variação da que foi proposta originalmente pela equipe de pesquisa do Doxa/Iesp em 1998.

\section{Endereço dos autores:}

Emerson Urizzi Cervi <ecervi7@gmail.com>

Universidade Federal do Paraná - Departamento de Ciências Sociais

Rua General Carneiro, 460, sala 907 - Centro CEP 80060-150, Curitiba, PR, Brasil

Michele Goulart Massuchin <mimassuchin@gmail.com>

Universidade Federal do Paraná

Rua XV de Novembro, 1299

CEP 80060-000, Curitiba, PR, Brasil 